\title{
1688: LA POLÍTICA INGLESA SE ABRE A LA MODERNIDAD
}

\section{8: THE ENGLISH POLITICS IS OPEN TO MODERNITY}

\author{
César Rodríguez Orgaz \\ Universidad Nacional de Educación a Distancia
}

Recensión de / Review of: Steven Pincus, 1688. La primera revolución moderna, Barcelona, Acantilado, 2013, 1.215 pp.

Palabras clave: 1688, Bill of Rights, Revolución Gloriosa, Inglaterra, historia constitucional inglesa, Modernidad, constitucionalismo.

Key Words: 1688, Bill of Rights, Glorious Revolution, England, English constitutional history, Modernity, constitutionalism.

1688. La primera revolución moderna "ha revolucionado" la interpretación de los acontecimientos desencadenados durante el relevo dinástico en Inglaterra a finales del siglo XVII. Que su autor es consciente de ello se aprecia al leer afirmaciones como: <<en lugar de una historia del triunfante excepcionalismo inglés, en la que se enfaticen las previsoras acciones de algunos hombres, cuenta una historia sobre una gran variedad de actores que reaccionan no sólo a los desarrollos en la alta política y en la Iglesia inglesa, sino a los cambios en la sociedad, en la economía y en la escena europea en general >> (p. 21). Se comprende, entonces, que el cambio de enfoque historiográfico es, en buena parte, responsable del cambio en la manera de entender la Revolución Gloriosa.

En cierto modo, el libro entabla una discusión con la narración clásica y escolar de esta Revolución, aquella que parte del historiador decimonónico Thomas Babington Macaulay, puesta por escrito en su History of England, y que refleja la interpretación whig de lo ocurrido en 1688 y 1689 describiéndolo como un giro político tan sutil como controlado $\mathrm{y}$, en todo caso, "incruento, artistocrático y consensuado". Por contraste, Pincus califica la Revolución de popular, violenta y causante de no pocas disensiones y escisiones (véase p. 835).

De este modo, Pincus, orientado desde un principio por una aproximación propia a lo ocurrido, se distancia de la interpretación al uso tras haberse documentado largamente en archivos y bibliotecas del Reino Unido, Estados Unidos y Europa continental. Una aproximación así inspirada en un enfoque holista, atiende a aspectos relevantes en materia de economía teórica, comercio exterior y desarrollo social; cuyo análisis le disuade de defender una perspectiva basada en el excepcionalismo inglés.

1688. La primera revolución moderna se estructura de acuerdo con cinco partes, junto con el capítulo preliminar y las conclusiones, que repasan los acontecimientos más trascendentes antes, durante y después del proceso revolucionario. La introducción se reserva a consideraciones generales sobre el significado y la lógica de una revolución política. El capítulo segundo, en torno a 
la Inglaterra prerrevolucionaria, traza un cuadro sobre la sociedad, la politica y el cristianismo en Inglaterra desde 1685. En la tercera parte el autor explica las razones por las que describe la Revolución como popular, violenta y disgregadora. La cuarta parte desarrolla las implicaciones de este giro histórico en la economía, la política exterior y las relaciones entre Iglesia y Estado. Por último, las conclusiones tratan de dar cuenta del alcance de la Revolución en la Modernidad.

Cierra el volumen una serie de apartados dedicados a notas, agradecimientos, referencias de las ilustraciones, abreviaturas, manuscritos consultados e indice de nombres y materias. En efecto, las páginas se salpican de un buen surtido de ilustraciones: mapas, monedas, grabados, naipes, etc. Las notas, por su parte, ocupan la nada despreciable suma de 279 páginas.

Esta edición en español es traducción del original 1688: The First Modern Revolution, publicada por primera vez en 2009 a cargo de la Yale University. La traducción de las 1.215 páginas que integran el libro, hojas casi de papel de Biblia, está firmada por Agustina Luengo Ferradas.

El doctor Steven Pincus enseña 17th and 18th Century British y European History en la Yale University. Sus áreas de interés comprenden la historia de Inglaterra en su modernidad temprana, los origenes del Imperio Británico, la emergencia del capitalismo, así como otros temas relacionados con la cultura, la economia, la politica y la intelectualidad de la Europa moderna. Entre sus publicaciones más notables destacan Protestantism and Patriotism: Ideologies and the Making of English Foreign Policy, 1650-1668, Cambridge: Cambridge University Press, 1996 o England's Glorious Revolution: A Brief History with Documents, New York: Palgrave Macmillan, 2006.

Hay que decir que el autor propone una lectura de la obra aquí reseñada desde tres perspectivas complementarias: la narrativa, la historiográfica y la conceptual; y, en función de ello, sugiere otras tantas formas distintas de abordarla.

La emergencia del Estado moderno supuso, por un lado, una serie de innovaciones en el arte de gobernar (centralización y burocratización del poder, profesionalización del ejército, crecimiento económico, definición del tejido social, etc.) y, por otro lado, un cambio de mentalidad respecto del pasado.

Consciente de lo borroso del concepto de Modernidad, Pincus, adoptando un sentido específico del término, reserva el adjetivo 'moderno' para referirse a aquellos cambios en la comprensión del Estado (particularmente el inglés) que modifican la práctica de la política exterior, la administración económica y la morfología social. A falta de una sola concepción del Estado moderno, se dieron distintas planificaciones sociopolíticas, que entraron en conflicto y estallaron con motivo de los sucesos revolucionarios. Ahora bien, interesa apuntar que $<<$ la modernización, en ésta como todas las revoluciones subsiguientes, era una causa, no una consecuencia de la revolución>> (p. 856).

A juicio de Pincus, la explicación de los acontecimientos aquí tratados se remonta a 1640 y tiempo atrás, cuando ciertos debates ideológicos empezaron a problematizar la manera de entender el Estado, de practicar la religión y de vivir en sociedad. De forma análoga, las consecuencias de la Revolución, radicales como fueron, se han prolongado durante no menos tiempo. Desde luego, si el autor habla de la Revolución Gloriosa como de un proceso empapado en sangre 
es porque fecha su origen en varias décadas atrás de 1688 . <<Las revoluciones no suelen producirse en meses, sino más bien en años. La restringida atención a los efectos inmediatos de los acontecimientos de 1688-1689 ha oscurecido las consecuencias radicales de la revolución $>>$ (p. 838, véase también p. 850). Después de todo, los grandes cambios socioeconómicos de la Inglaterra de los siglos XVII y XVIII se desplegaron a través de un proceso comprendido en largos decenios. Ignorar esto, como hizo Macaulay, implica hacer caso omiso de gran parte de las causas socioeconómicas de la Revolución y concluir, en consecuencia, que este acontecimiento nunca supuso una ruptura absoluta con la tradición.

Como se ha comentado más arriba, este libro representa una réplica a la autocomplaciente historiografia del establishment whig. Se trata, así, de una interpretación revisionista a su manera que abandona la lectura de la Revolución en términos progresistas para mostrarla como una lucha de poder entre facciones rivales. <<La Revolución Gloriosa no fue el triunfo de un grupo de modernizadores sobre los defensores de la sociedad tradicional. Más bien enfrentó a dos grupos de modernizadores. Ambas partes procuraron, contra todo pronóstico, apelar a los corazones y las mentes de los reaccionarios. Creo que ésta fue una pauta típica de todas las revoluciones modernas $>>$ (p. 19, ver también p. 837). Según Pincus, los revolucionarios, en la Edad Moderna, prescinden de la idea de predicar una ruptura con la tradición y, en lugar de ello, rivalizan por vender su proyecto como la mejor opción de renovación social. Al involucrar a grandes segmentos de la población, Englishmen a los que era necesario ganar para la causa, la Revolución se convirtió en un conflicto partidista, precursor en este sentido de las revoluciones del siglo XVIII en Francia y Norteamérica. Así se mide, en opinión del autor, el peso histórico de 1688. De hecho, Pincus se refiere a los acontecimientos que entronizaron a Guillermo III como "la primera revolución moderna" y habla de ella como causa de una crisis en la historia del país anglosajón (véanse pp. 17, 22, 834, etc.).

Decimos que el revisionismo del autor tiene su propios argumentos porque él mismo también se esfuerza por singularizarse de aquellos revisionistas que $<<$ cometen el error de centrarse estrictamente en los temas religiosos. Aunque dichos temas eran importantes tanto para Jacobo II como para sus oponentes, no eran los únicos asuntos que los animaban $>>$ (p. 844). Unos (los historiadores whig) y otros (los historiadores reduccionistas que sobreestiman el punto de vista religioso) comparten el excepcionalismo inglés: la idea de que Inglaterra estaba aislada del continente tanto en lo físico como en lo espiritual. Pincus pone en cuestión esta tesis asegurando que los revolucionarios estaban motivados por una concepción ideológica más amplia y llega a señalar que $<<$ la Revolución Gloriosa no fue una lucha entre católicos y protestantes $>>$ (p. 843). La comprensión correcta exige una mirada más bien pluridireccional, atenta al conjunto de los aspectos sociales, culturales, económicos e históricos de lo ocurrido.

El autor reivindica una reintegración histórica, en contraste con lo que él mismo define como hiperespecialización de la historia, producto de todos aquellos investigadores que han parcelado la materia bruta de estudio cultivando separadamente la historia religiosa, la constitucional, la social, etc. Identificar las causas de los cambios y procesos históricos exige entender que $<<$ los hombres y 
las mujeres [...] experimentaban sus vidas como una totalidad. Es hora de que los historiadores vuelvan a escribir la historia sin más >> (p. 856).

Sobre esa base, Pincus considera que los actores protagonistas de la Revolución no fueron los católicos o los protestantes, sino los burgueses y, en particular, los comerciantes. Sostiene que <<se justifica la comprensión de la revolución de 1688-1689 como una revolución burguesa en un sentido cultural y político >> (p. 851); pero no porque existiese una clase burguesa cohesionada y autoconsciente, sino porque Inglaterra estaba convirtiéndose en una sociedad mercantilista en la que los comerciantes pasaron a ser auténticos creadores de opinión. Gracias al impulso revolucionario, el país avanzó desde una forma de gobierno basada en principios patrimoniales hacia un modelo político impregnado de crecientes valores burgueses y comerciales: cultura urbana, fomento de la manufacturación, imperialismo económico, etc.

Así pues, la herencia que dejaron los revolucionarios de 1688 puede sinterizarse en tres capítulos esenciales: reforzamiento de la política exterior de Inglaterra, sustitución de las prioridades económicas y reconfiguración de la Iglesia anglicana.

Enviado el (Submission date): 5/10/2014

Aceptado el (Acceptance date): 8/12/2014 